Grounded
Cutbacks mean that
Venus Express gets
its wings clipped
p474

\title{
Priorities for genome sequencing leave macaques out in the cold
}

\section{Erika Check, Washington}

The chimpanzee, chicken and honeybee are among the top priorities for genome sequencing selected by the National Human Genome Research Institute (NHGRI) in Bethesda, Maryland. The announcement on 22 May sparked equal measures of jubilation and despair among researchers who had been lobbying the institute to fund projects for their favourite organism.

Other priorities include the sea urchin Strongylocentrotus purpuratus and the protozoan Tetrahymena thermophila. Fifteen fungi make up the remainder of the list.

There will be arguments among scientists about each selection, but the main point of controversy is the choice of the chimpanzee ahead of the rhesus macaque, which is more widely used in biomedical research but is listed as only a "moderate" priority.

The main NHGRI-funded sequencing centres - at the Whitehead Institute for Biomedical Research in Cambridge, Massachusetts, Washington University School of Medicine in St Louis, Missouri, and Baylor College of Medicine in Houston, Texas are fully occupied with the human, mouse and rat genomes. But as these projects wind down over the coming months, spare

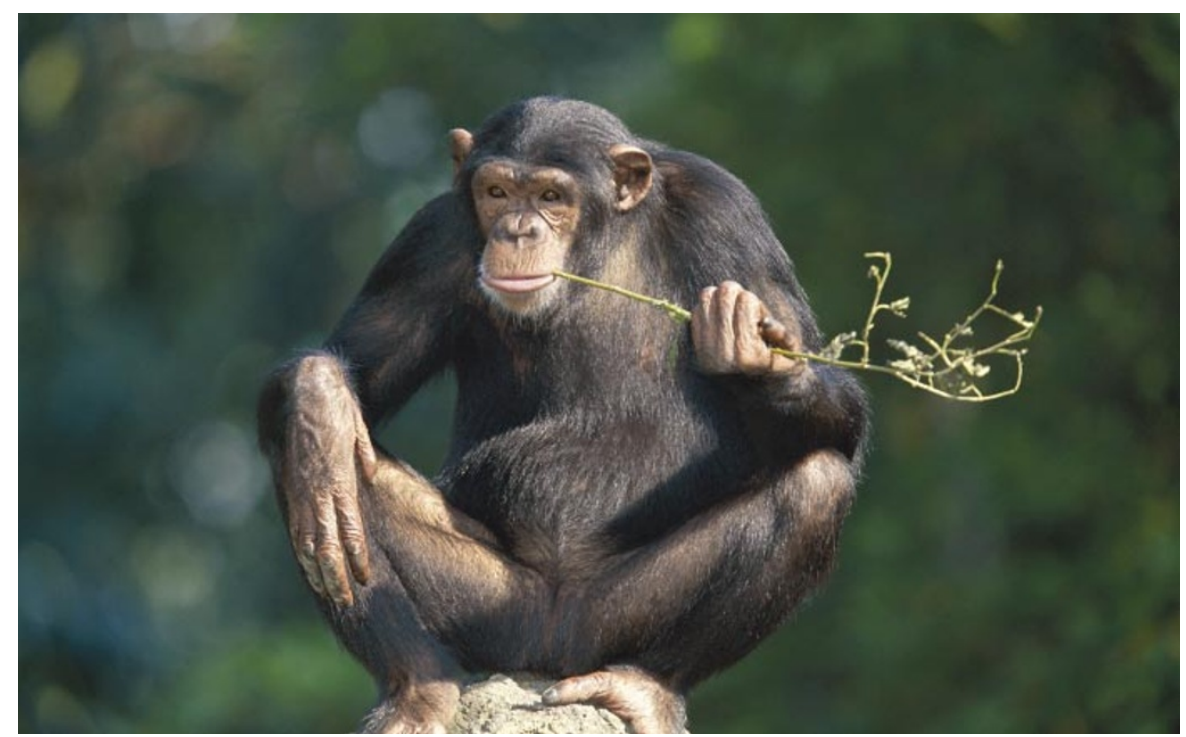

Bright idea? Comparing the chimp and human genomes could shed light on human cognitive abilities.

sequencing capacity will open up, so the NHGRI asked researchers to submit 'white papers' making the case for the next round of organisms to be sequenced. An expert panel reviewed a list of 13 bids, ranging from the green turtle to the cow.

Individual sequencing projects will still have to be approved one by one. But given the immense opportunities offered by genomics, advocates of particular model organisms had invested high hopes in getting onto the NHGRI's priority list. "Working on a system that doesn't have a sequence available is like doing research with one hand tied behind

\section{Investigation into nanotechnology papers expands}

\section{Geoff Brumfiel, Washington}

The probe into alleged data falsification by one of the brightest stars in nanotechnology is widening. Over the past week, the number of papers under investigation has more than doubled, as scientists scrutinize the publications of Jan Hendrik Schön of Bell Laboratories in Murray Hill, New Jersey.

Nanotechnology researchers were stunned when news broke that some of Schön's papers on electronic devices made from organic molecules were being investigated. Graphs in separate papers describing the behaviour of different devices, operating under different conditions, contained plots that were apparently identical (see Nature 417, 367-368; 2002).

On 16 May, when Bell Labs announced that a panel headed by physicist Malcolm Beasley of Stanford University in California would lead the investigation, five papers three in Science, one in Nature and one in Applied Physics Letters - were under suspicion. Another Science paper was soon added to the list.

And with researchers submitting additional papers to the panel, the total had risen to 14 by Nature's press deadline earlier this week. They include papers in Physical Review B, Synthetic Metals, Thin Solid Films and Physica Status Solidi B. Most were published in the past two years, although two date from 1998.

"We will look into all substantive allegations," says Beasley. But the panel will not examine Schön's entire published output, which extends to more than 100 papers.

The researchers who found the first suspect figures say that they are now quitting the search. "I think the issues have been raised," says Paul McEuen of Cornell University in Ithaca, New York. Lydia Sohn of Princeton University in New Jersey adds: "All of us are kind of burnt out. If people find more, I hope they will submit them to the panel." 
your back," observes Eric Green, director of the NHGRI's own sequencing centre.

The priorities highlight animals useful in agriculture, such as the chicken and the honeybee, but not plants, for which sequencing projects are funded by the National Science Foundation and the US Department of Agriculture. The agriculture department is also expected to collaborate with the NHGRI in work on the chicken and honeybee genomes.

Fungi are included because they cause human and agricultural disease. Both the sea urchin and the chicken are model organisms for developmental biologists, and Tetrahymena is used in cell biology and genetics research, particularly for studies of the telomeres that cap the ends of chromosomes, which shorten as cells age. "The biologists who work on these organisms are really energized by this," says Richard Gibbs, director of Baylor's sequencing centre.

Members of the selection panel say they tried to select a range of organisms to allow evolutionary and comparative studies. Advocates for the chimpanzee, which is thought to have a genome $98.5 \%$ genetically identical to our own, argue that comparisons between the two sequences could yield clues about the origin of human cognitive abilities and language. They also say that the sequence could help to explain why chimpanzees do not get diseases such as breast cancer and Alzheimer's - offering potentially important medical insights.

But these arguments cut little ice with researchers who have been lobbying for the rhesus macaque to be made the top-priority primate. Macaque advocates feel that the panel was swayed by the public appeal of sequencing our closest relative, and point out that scientists can do little work on chimpanzees because of welfare concerns and the animals' endangered status.

"It is a tragedy that the NHGRI is committing these resources to sequencing the chimpanzee genome when there are so many investigators using rhesus monkeys who desperately need a sequence to advance research," says John VandeBerg, director of the Southwest National Primate Research Center in San Antonio, Texas. He argues that rhesus macaques provide vital models in research on many human diseases. They are particularly important in attempts to develop vaccines against HIV, and are widely used in basic neuroscience studies.

But the macaque might still win favour in the future. The NHGRI's priorities pane will review white papers three times a year from now on. And researchers can revise and resubmit their proposals, says Jane Peterson, programme director for largescale sequencing at the NHGRI. "We don't consider the high-priority bin to be static," she says.

www.nhgri.nih.gov/NEWS/sequencing.html

\section{Delays and cutbacks kill off Europe's mission to Venus}

\section{Quirin Schiermeier, Munich}

There was good and bad news last week for Europe's space scientists. Two projects believed to have been under threat - a mission to map star positions precisely and another to study the Sun — survived a meeting of European Space Agency (ESA) officials. But plans to send a spacecraft to Venus in 2005 were axed amid doubts over the project's timetable.

The demise of the Venus Express mission came in Ardenes in arctic Norway, where ESA's Scientific Programme Committee met to reassess the agency's scientific activities for the next 10 years. ESA has to save up to 200 million euros (US\$184 million) during that period in response to budget cuts imposed last year by its members, which comprise 15 European states plus Canada (see Nature 415, 730; 2002).

Venus Express was to have carried out the first global survey of Earth's nearest planetary neighbour, including studies of its atmosphere and its interactions with the solar wind, the stream of charged particles emitted by the Sun. The mission had the potential to save money by using the same production facilities as Mars Express, an ESA mission that is scheduled to launch next year.

In the end, Venus Express was dropped because of diverging time schedules, says Giovanni Bignami, scientific director of the Italian Space Agency and outgoing vicechair of the Scientific Programme Committee. The mission needed to be launched very shortly after Mars Express if the two were to share facilities, but funding for the spacecraft's 20-million-euro payload of scientific instruments, which was to come from individual member states, had still not been secured.

The decision shocked those involved with the project, and has left planetary scientists feeling cheated. "It came out of the blue," says Dimitri Titov, a physicist at the Max Planck Institute for Aeronomy in KatlenburgLindau, Germany, and science coordinator for the cancelled mission. "We are losing a huge opportunity to study an underexplored planet."

"It is absolutely regrettable," agrees Michael Grewing, director of the Institute for Millimetre Radiowave Astronomy in Grenoble, and chair of the group of space scientists that advises ESA. His panel had argued in favour of the project. "We have missed the unique opportunity of putting together a full-range planetary mission for just one-third of the usual costs."

Grewing points out that Venus Express would have fitted well in the six-year gap

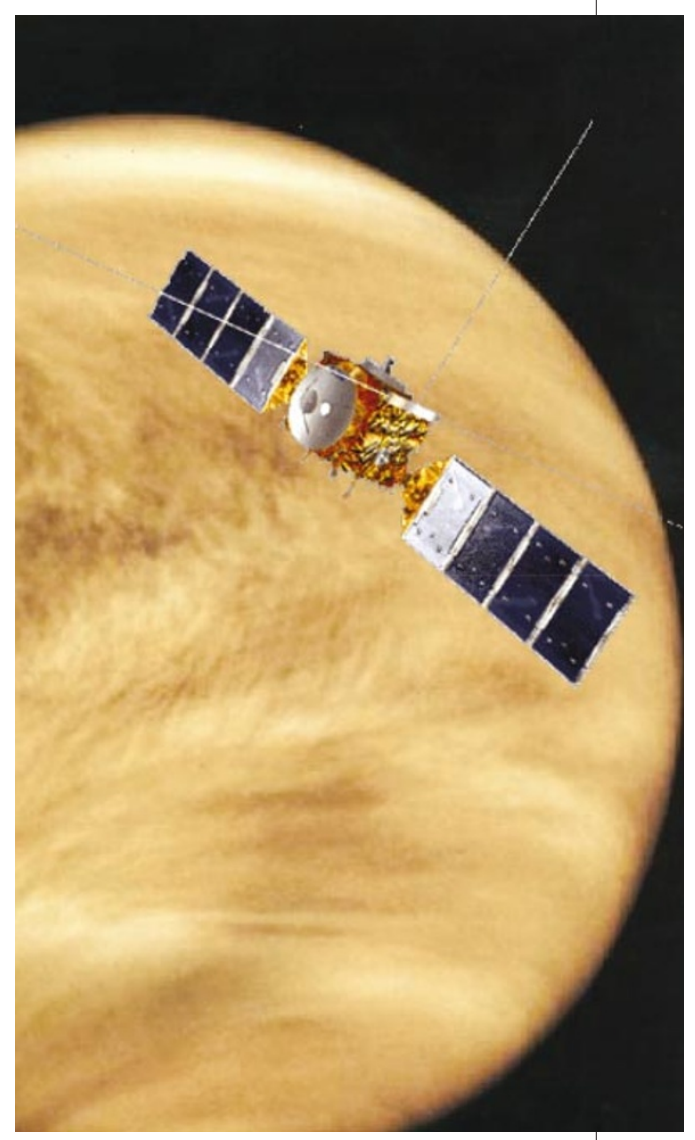

Missed chance: Venus Express was originally expected to share facilities with Mars Express.

between the launches of Mars Express and Bepi Colombo, the planned 2009 mission to Mercury. He says that ESA should now look for ways to help Solar System researchers, such as increasing European participation in planetary missions run by NASA.

Two projects that ESA officials had previously hinted could be axed were retained at the Norway meeting. GAIA, an advanced astrometry satellite that will precisely map the brightness, colour and relative positions of a billion objects in the sky, could be launched by 2009 if development of the spacecraft's instruments can be completed in time. Space scientists hope that data from GAIA will improve their understanding of stars' inner workings, and help them to detect possibly tens of thousands of extrasolar planets, including small, Earth-like ones. Solar Orbiter, which will study the Sun from a distance of around one-fifth of the Earth's solar orbit, will be launched between 2008 and 2013 as planned.

GAIA

astro.estec.esa.nI/GAIA

Solar Orbiter

sci.esa.int/home/solarorbiter/index.cfm 